\title{
Screening for polycystic kidney disease: importance of clinical presentation in the newborn
}

\author{
L S TAITZ, C B BROWN, C E BLANK, AND G M STEINER
}

Departments of Paediatrics and Radiology, The Children's Hospital, Department of Nephrology, Royal Hallamshire Hospital, and Department of Medical Genetics, Sheffield

SUMMARY Fifty per cent of the offspring of adults with the adult (dominant) form of polycystic kidney disease are carriers of the abnormal gene. Clinical symptoms and signs before adolescence are rare, but renal ultrasonography may detect evidence of cyst formation. Twenty two children, all offspring of parents with known adult polycystic kidney disease, have undergone renal ultrasonography. In six cases evidence of disease was detected without clinical manifestations at the ages of $1,2,5,8,13$, and 14 years. There were no renal masses, hypertension, haematuria, or evidence of renal insufficiency.

In four children from three sibships, whose families had no previous history of renal disease, bilateral renal masses were noted to be present at birth. In each case one parent was subsequently found to have adult polycystic kidney disease. At the ages of $1,4,6$, and 20 years, while renal masses were still palpable, there was no evidence of renal insufficiency or hypertension in the younger children, while the oldest had mild renal failure. An analysis of the reported cases in childhood is suggestive of a bimodal distribution of enlarged kidneys, with a number of cases diagnosed at birth or soon after, followed by an increasing incidence during later childhood. Adult polycystic kidney disease presenting at birth may be qualitatively different from the disease detected by screening programmes of children at risk.

The adult, dominant form of polycystic kidney disease is rarely diagnosed clinically in childhood. As recently as 1976 an eminent nephrologist and expert in childhood hypertension could claim never to have made the diagnosis in childhood and was unable to find a single case with nephromegaly or impaired renal function, or both, in the records of the Los Angeles Children's Hospital or among more than 5000 autopsies. ${ }^{1}$

The advent of renal ultrasonography has introduced a safe, non-invasive method for detection of adult polycystic kidney disease, raising issues about whether the offspring of parents with known disease should be routinely screened, at what age it should begin, and how often it should be carried out. Current major paediatric texts express no opinion on this important issue. ${ }^{23}$

All potential carriers of the adult disease gene should be offered screening before starting their own families on the basis of informed choice and understanding its nature. As clinical presentation in childhood is rare it remains uncertain how early such screening should begin.
We report our experience with children of parents with adult polycystic kidney disease. Our findings are, we believe, useful in helping paediatricians arrive at a rational approach to this problem. We also present data and observations on cases presenting with renal masses in the newborn period.

\section{Patients and methods}

The study included two groups of children. The first group comprised subjects referred for screening because one parent was known to have adult polycystic disease of the kidneys. The second group comprised children who were found to have renal masses at birth and one of whose parents was subsequently found to have the disease. These two groups are considered further below.

Group 1. Twenty two subjects, from 16 sibships, underwent ultrasonic screening. Ultrasound was carried out at various times until diagnosis had been established. Additional investigations included regular blood pressure determinations, urine analysis, and tests on blood creatinine concentrations. 
Patients with the ultrasound evidence of disease diagnosed on screening all had the characteristic features of renal cysts-that is, a non-reflective area with sonic enhancement behind it. There was no case of hyperreflective large kidneys resembling the recessive form of polycystic disease usually diagnosed in the neonatal period.

Group 2. This comprised four children followed up for varying periods who had been noted to have renal masses at birth and in whom both the child and one parent were found to have characteristic ultrasound/radiological features.

\section{Results}

Group 1. The mean age of the children at their most recent screening was $\mathbf{6 . 2 5}$ years, with a range of 1 to 18 years. Six of the 22 cases $(27 \%)$ have been identified as carriers of the gene at $1,2,5,8,13$, and 14 years, respectively. None of these children had renal masses or other clinical evidence of disease. Two other children had solitary renal cysts of uncertain importance and a further two had had at least one episode of microscopic haematuria at 1 year of age in each case but with normal ultrasonic findings. Whereas under the age of 1 year there were no cases detected, in the age ranges $1-4,5-8$, and $9+$ about one third of the children were found to have unequivocal ultrasound evidence of abnormality. The age of first screening and diagnosis or last negative screening are listed in Table 1.

Blood pressure and creatinine concentrations were within the normal range in all screened cases. In no case was systolic or diastolic pressure above the 95th centile of the American task force on blood pressure in childhood at last measurement. Mean systolic blood pressure was $100 \mathrm{~mm} \mathrm{Hg}$ (median 105 $\mathrm{mm} \mathrm{Hg}$ ), with a range of $80-160 \mathrm{~mm} \mathrm{Hg}$, while that for diastolic blood pressure was $62 \mathrm{~mm} \mathrm{Hg}$ (median $65 \mathrm{~mm} \mathrm{Hg}$ ), with a range of $50-80 \mathrm{~mm} \mathrm{Hg}$. Three children had had urinary tract infections. Of these, one had a positive ultrasound scan. Blood urea and creatinine concentrations were within the normal range in all the children.

Group 2. Of the children diagnosed by the presence of renal masses at birth, one case had hypertension during the first year of life (maximum blood pressure 160/100), but this settled to normal at 18 months and has remained normal to the age of 6 years. One of the four patients found to have renal masses at birth was in moderate renal failure at 20 years of age (serum creatinine concentration 200 $\mu \mathrm{mol} / \mathrm{l})$. Table 2 summarises the state of these four children.
Table 1 Details of children screened by ultrasound for adult polycystic kidney disease with an affected parent

\begin{tabular}{|c|c|c|c|}
\hline \multirow[t]{2}{*}{ Sibship } & \multicolumn{3}{|l|}{ Age (years) } \\
\hline & $\begin{array}{l}\text { When first } \\
\text { screened }\end{array}$ & $\begin{array}{l}\text { When last } \\
\text { screened }\end{array}$ & $\begin{array}{l}\text { At positive } \\
\text { diagnosis }\end{array}$ \\
\hline 1 & 6 & 9 & - \\
\hline $2 a$ & 6 & 7 & - \\
\hline $2 b$ & 9 & 9 & - \\
\hline 3 & 8 & 8 & 8 \\
\hline $4 a$ & 11 & 13 & - \\
\hline $4 b$ & 16 & 18 & - \\
\hline 5 & $<1$ & 2 & $-\dagger$ \\
\hline 6 & 1 & 1 & -+ \\
\hline $7 a$ & 2 & 2 & - \\
\hline $7 b$ & 5 & 5 & - \\
\hline 8 & 2 & 3 & - \\
\hline 9 & $<1$ & 2 & $2^{*}$ \\
\hline $10 a$ & 2 & 5 & - \\
\hline $10 \mathrm{~b}$ & 3 & 3 & - \\
\hline 11 & Birth & 1 & - \\
\hline $12 a$ & 13 & 13 & 13 \\
\hline $12 \mathrm{~b}$ & 14 & 14 & 14 \\
\hline $13 a$ & Birth & 1.5 & 1.5 \\
\hline $13 b$ & Birth & 2 & - \\
\hline 14 & 2 & 2 & 2 \\
\hline 15 & 7 & 7 & $7^{*}$ \\
\hline 16 & 5 & 5 & 5 \\
\hline
\end{tabular}

*Single cyst only.

+Single episode of microscopic haematuria.

Table 2 Details of the four children with adult polycystic kidney disease diagnosed by presence of renal masses at birth

\begin{tabular}{llll}
\hline & Outcome & $\begin{array}{l}\text { Affected } \\
\text { parent }\end{array}$ & Renal function \\
\hline 1a & Well at 6 years & Father & Normal \\
1b & Well at 1 year & Father & Normal \\
2 & Well at 4 years & Father & Normal \\
3 & Alive at 20 years & Mother & Moderate failure \\
\hline
\end{tabular}

\section{Discussion}

There have been varying reports on the prevalence of clinical features of the adult disease in childhood. ${ }^{4-6}$ Most reported cases have been neonates with renal masses. Onset of clinical disease in later infancy and childhood is rarely described..$^{7-9}$

Pathological material either after death or obtained surgically have formed the basis of other studies. Blyth and Ockenden studied 29 cases of renal cystic disease and found six had the adult form. ${ }^{10}$ Four were liveborn and two were twin abortuses from a family with a history of cystic kidney disease. There are isolated reports of newborns or neonates who have been found to have cystic kidneys of the dominant type. ${ }^{11}{ }^{12}$ In a similar category are other stillbirths and abortuses with cystic kidneys. ${ }^{10}$ 
Cases may be detected during screening of the offspring of adults with disease or a family history of disease. One such study included 59 children under the age of 12 years among 495 relatives. ${ }^{13}$ Sixteen had disease and 10 were considered suspicious, almost reaching the expected prevalence of $50 \%$. There are no details of the ages of the children and whether they had renal masses. Another study of 3379 individuals from 62 families included one infant found to have an abdominal mass at birth. ${ }^{14}$ Of 15 subjects screened under 15 years of age, all were negative. This study gives the probability for positive diagnosis between 15 and 19 as $30 \%$ (10 out of 33 screened).

In another investigation two cases under 10 years (both negative) and 20 between 11 and 20 years (three positive) were screened. ${ }^{15}$ The authors concluded that screening by ultrasound between 10 and 20 years will identify about $30 \%$ of the potential cases. Rosenfield et al detected renal cysts in 14 of 37 cases between the ages of 18 months and 32 years. ${ }^{16}$ Bear et al studied 17 kindreds containing a total of 388 persons. ${ }^{17}$ Of these, 41 were under 10 years, but only 18 underwent ultrasound examination and two cases were positive. Of individuals between 10 and 19,43 of 69 underwent ultrasound examination and 14 cases were found to be positive. A similar study by Sahney et al on 26 cases, of whom 24 were under 25 years, found 17 to be positive on ultrasound examination. ${ }^{18}$ Five of the cases were under 15 years and one of these, aged 9 years, was positive. Walker et al found 11 positive cases out of 22 children aged 5-17 years by a combination of ultrasound, nephrotomography, or pyelography. ${ }^{19}$

These series lack the clinical information to allow an opinion to be formed regarding the optimal time to carry out screening in children under 10 years. Our own data indicate that ultrasound examination alone will detect about $70 \%$ of the expected cases in a group of children between 1 and 14 years but that with present methods screening otherwise normal babies before 1 year of age is probably not worth while.

Whether an early diagnosis is justified remains an open question. The parents of most of the cases reported here requested screening for their children and expressed a desire to know as soon as possible whether their child was affected or not. The only parent who stated she would rather not have known was the mother of one of the babies found to have renal masses at birth. The knowledge that their child has a $50 \%$ chance of being affected seems to be a spur to early identification. In the two cases with single cysts the doubtful importance of the finding was explained with a recommendation for repeat ultrasound in five years.
Ultrasound examination at 1 year and then again at 5 years, followed by five yearly repeats, seems to be a reasonable programme in those families who, understanding the pathogenesis of the disease, still wish to have their children screened at an early age.

It is of interest that while there are more than 20 reported cases presenting with renal enlargement at birth or soon after, there is a relative dearth of reported cases in later infancy and childhood. In the present series, for example, whereas large renal masses were present in the four cases diagnosed at birth, the kidneys were not clinically enlarged in any of the patients diagnosed by ultrasound screening, a finding noted previously. ${ }^{1}$ Renal masses are described as the commonest clinical presentation in childhood, but this occurs mainly in the neonatal period. There is no indication in the published reports of the steady increase in numbers of cases with masses that might have been anticipated. The age distribution of reported cases of renal masses seems to be bimodal (Figure). This may be due merely to under reporting, but against this explanation is the fact that among those children who have been detected by screening as positive, enlargement of the kidneys is not a feature.

The cases with renal masses in the neonate possibly represent a distinctive group. These

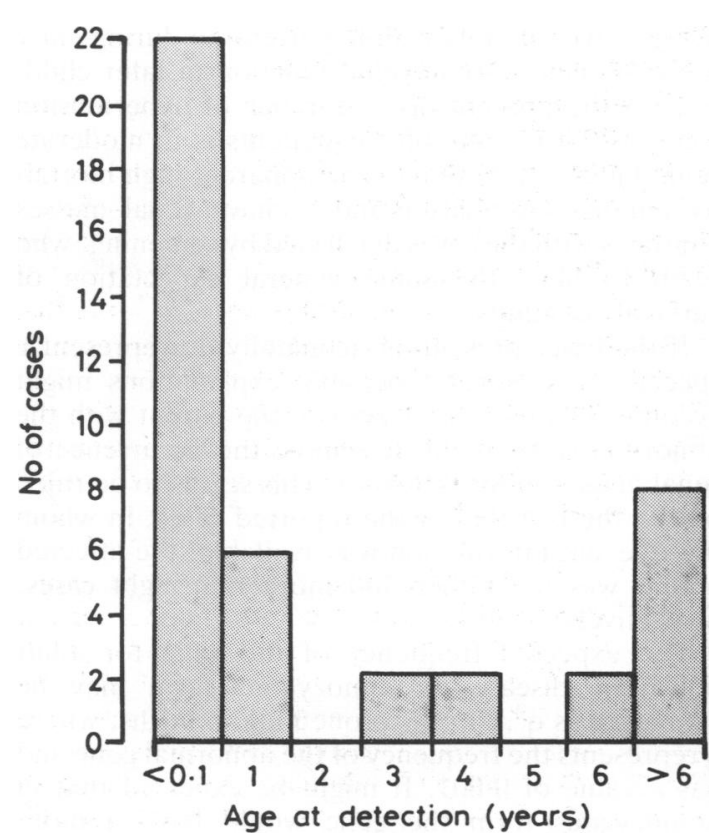

Figure Age at detection of renal masses of children with adult polycystic kidney disease (reported cases). 
neonatal cases include those where death occurred for various perinatal reasons and cystic disease of the kidneys was detected incidentally at postmortem examination. Apart from abortions and stillbirths there are three such cases reported and in none are the kidneys stated to have been clinically enlarged. One was a child detected by prenatal ultrasound examination, presumably as a result of routine screening. ${ }^{20}$

Other neonates suffered early deaths or renal failure related to renal disease. One case with Potter's syndrome and renal masses at birth died of pulmonary oedema due to severe hypertension at 7 months. Another died in renal failure at 3 months, having been noted to have renal masses at 2 weeks. One of the children described by Proesmans et al was found to have renal masses and hypertension soon after birth and was in moderate renal failure at 7 years of age. ${ }^{12}$ In all these cases the cause of death or renal failure seems to have been due to severe early adult polycystic kidney disease. Of 25 infants found to have renal masses at birth, eight had died of perinatal events not related to their kidney disease, while seven were either in renal failure or had died of complications of their renal disease, before the age of 8 years. ${ }^{21}$ The neonatal form of the disease (renal masses at birth) seems to have a bad prognosis, yet those cases who did not develop early signs of deterioration seemed to be very well with no evidence of impaired renal function as late as 9 years of age. Even infants with hypertension during early life may have normal renal function in later childhood with apparent disappearance of hypertension (our case 1b) ${ }^{4}$ One of our patients is in moderate renal failure at 20 years. The apparent high mortality among newborns found to have renal masses contrasts with the cases diagnosed by screening, who seem to have the same general expectation of survival as adults.

If the cases presenting neonatally do represent a special group several possible explanations might account for this. The gender of the parent with the abnormal gene might determine the occurrence of renal masses in the newborn. This seems to be ruled out by the fact that of the reported cases, in whom the relevant information was available, the affected parent was the father and mother in eight cases, respectively.

The expected frequency of the gene for adult polycystic disease in homozygous form may be estimated as $\mathrm{q}^{2}$, or one in one million births, where $q$ represents the frequency of the abnormal gene and has a value of 0.001 . It might be expected that in homozygous form the gene would have a more severe effect. In no case presenting in the newborn, however, has both parents been shown to have the gene. There seem to be no reported cases of putative homozygous disease.

The same individual might have in heterozygous form both the gene for the adult variety and that for autosomal recessive polycystic disease of the kidney. If allelic then both genes would be expected to occur in the same individual with a frequency of $2 \mathrm{qr}$, or six in a million births, where $r$ represents the frequency of the gene for recessive polycystic disease and has a value of 0.003 . If not allelic then the frequency would be $2 \mathrm{pq} \times 2 \mathrm{pr}$, or 12 in a million births. In either case manifestation might be more 'severe' than in simple heterozygous adult polycystic kidney disease. Either hypothesis would account for the fact that in no fewer than three families there have been siblings reported with neonatal renal masses, an extraordinary coincidence for what is an extremely rare presentation. ${ }^{22} \mathrm{An}$ incidence of 6-12 per million is not inconsistent with the apparent frequency of renal masses due to apparent adult polycystic disease in the newborn.

While ultrasonography remains at present the most effective screening procedure it may well be that the development of gene probes based on the discovery of genetic markers closely linked to adult polycystic disease on chromosome 16 will eventually replace it. ${ }^{2.3}$ This is a technology for the future rather than the immediate present.

\section{References}

I Licbermann E. Clinical pediatric nephrology. Philadelphia: JB Lippincott, 1976:356.

2 Houston IB, Winberg J, Arncil GC, White RHR, Murphy RV. Disorders of the urogenital system: polycystic discase. In: Forfar JO, Arneil GC, eds. Textbook of paediatrics. 3rd ed. Edinburgh: Churchill Livingstone, 1984:1017-8.

3 Drummond KN. Adult type polycystic kidneys. In: Behrman RE, Vaughan VC, eds. Textbook of pediatrics. 12th ed. Philadelphia: W B Saunders, 1983:1357.

4 Kaye C, Lewy P. Congenital appearance of adult-type (autosomal dominant) polycystic kidney discase. $J$ Pediatr 1974;85:807-11.

5 Eulderink F. Hogewind BL. Renal cysts in premature children: occurrence in a family with polycystic kidney disease. Arch Pathol Lab Med 1978;102:592-5.

6 Kaplan BS, Rabin I, Nogrady MB, Drummond KN. Autosomal dominant polycystic renal disease in children. $J$ Pediatr 1977;90:782-3.

7 Farrell TP, Boal DK, Wood BP, Dagen JE, Rabinowitz R. Unilateral abdominal mass: an unusual presentation of autosomal dominant polycystic kidney disease in children. Pediatr Radiol 1984;14:349-52.

$\checkmark$ Ross DG, Travers H. Infantile presentation of adult-type polycystic kidney discase in a large kindred. J Pediatr 1975;87: $760-3$

${ }^{9}$ Stickler GB, Kelalis PP. Polycystic kidney disease: recognition of the "adult form" (autosomal dominant) in infancy. Mayo Clin Proc 1975;50:547-8.

10 Blyth H, Ockenden BG. Polycystic discase of kidneys and liver presenting in childhood. J Med Genet 1971;8:257-61. 
1 Chevalier RL. The neonate with adult-type autosomal dominant polycystic kidney disease. Int J Pediatr Nephrol 1981:2:73-7.

12 Proesmans W, Van Damme B, Casaer P, Marchal G. Autosomal dominant polycystic kidney disease in the neonatal period: association with a cerebral arteriovenous malformation. Pediatrics 1982;70:971-5.

13 Gabow PA, Ikled W, Holmes JH. Polycystic kidney disease: prospective analysis of non-azotaemic patients and family members. Ann Intern Med 1984;101:238-47.

${ }^{14}$ Milutinovic J, Fialkow PJ, Phillips LA, et al. Autosomal dominant polycystic kidney disease: early diagnosis and data for genetic counselling. Lancet 1980;i:1203-5.

15 Hogewind BL, Veltkamp JJ, Koch CW, De Graeff J. Genetic counselling for adult polycystic disease: ultrasound as a useful tool in presymptomatic diagnosis. Clin Genet 1981;18:168-72.

16 Rosenfield AT, Lipson HH, Wolf B, Taylor KJW, Rosenfield NS, Hendler E. Ultrasonography and nephrotomography in the pre-symptomatic diagnosis of dominantly inherited (adult onset) polycystic kidney disease. Radiology 1980;135:423-7.

17 Bear JC. McManamon P, Morgan J, et al. Age at clinical onset and at ultrasonographic detection of adult polycystic disease. Am J Med Genet 1984;18:45-53.

${ }^{18}$ Sahney S, Sandler MA, Weiss L, Levin NW, Hricak H,
Madrazo BL. Adult polycystic disease: presymptomatic diagnosis for genetic counselling. Clin Nephrol 1983;20:89-93.

19 Walker FC. Loney LC, Root ER. Melson GL. McAlister WH. Cole WH. Diagnostic evaluation of adult polycystic disease in childhood. American Journal of Radiology 1984:142:1273-7.

${ }^{20}$ Garel L, Sauvegrain J, Filiatrault D. Dominant polycystic disease of the kidney in a newborn child: report of one case. Ann Radiol (Paris) 1983:26:183-6.

21 Main D, Mennuti MT, Cornfield D, Coleman B. Prenatal diagnosis of adult polycystic kidncy disease. Lancet 1983;ii: $337-8$.

22 Loh JP, Haller JO, Kassner EG, Alani A, Glassberg K. Dominantly inherited polycystic kidneys in infants: association with hypertrophic pyloric stenosis. Pediatr Radiol 1977;6:27-31.

23 Reeders ST, Breuning MH, Corney G, et al. Two genetic markers closely linked to adult polycystic kidney disease on chromosome 16. Br Med J 1986:292:851-3.

Correspondence to Dr L S Taitz, Department of Paediatrics, The Children`s Hospital, Western Bank, Sheffield S10 2TH, England.

Received 5 August 1986

British Paediatric Association

Annual meetings
At York University:
1987 April $7-10$
1988 April $12-16$
1989 April 11-15
At University of Warwick:
1990 April 3-7
1991 April 16-20
1992 April 7-11
1993 April 19-23 (provisional)
1994 April 11-15 (provisional)

